\title{
Preface
}

The seeds of this book began germinating on the campus of the University of California, Berkeley, in the fall of 2006 . The occasion was a symposium on Bolivar and the Bolivarian revolution in Venezuela, in which anthropologist Charles Briggs and physician Clara Mantini-Briggs presented research on Misión Barrio Adentro, a revolutionary healthcare program developed on the Cuban model. Interviews with barrio residents showed how experiences in clinics had modified the relationship between Venezuela's citizens and the Bolivarian state. That the manner in which citizens were recognized in healthcare initiatives might shape the provision of care brought me back to the socially distinct settings of colonial Mexico, where efforts to introduce immunizations and other measures of disease control at the end of the eighteenth century dovetailed with intermittent programs to acculturate rural pueblo de indios. I hoped to understand the role of politics and culture in a field that seemed enamored with frameworks of biopolitics, medicalization, and medical hybridity.

As in Venezuela, the relationship of the Bourbon state to subjects and tributaries in Mexico was in flux. In these years of scientific discovery and debate, the manner in which immunization would be introduced and used looked as uncertain as the political scene in the wider Atlantic world. These are times when the future seems to offer possibilities that the socioeconomic structure might not ultimately allow. Revolutions in medicine, like other kinds, have a way of doubling back, returning, revolving. But the contingent moment, to use the technical term, with its anticipation that things might be otherwise, holds out the promise of insights about technology, citizenship, and ways of knowing that can inform other humanities disciplines, the human sciences, and the way we think about the politics of health care and immunity today. How are new medical techniques and measures designed and implemented? What insights and sensibilities do ordinary people contribute to the process? Enlightened Immunity attempts an answer. The book explores the ways that heterogeneous communities and cultures are made visible across fragmented 
regions, the different forms in which medicines, practitioners, and preventive paradigms reach them, and the mediation of subjects and their knowledge, following the Colombian communication studies scholar Jesús Martín-Barbero, through performances, protests, processions, and ritual.

In the course of completing it, I have incurred numerous personal and professional debts. The financial support of the University of California's Chancellor's Fund, the University of California Institute for Mexico and the United States (UC MEXUS), the Mabelle McLeod Lewis Memorial Fund, and the Muriel McKevitt Sonne Chair made possible extended research trips to archives and libraries. The Dana and David Dornsife Fellowship at the Huntington Library, San Marino, California, facilitated a research leave in 20I2-20I3 to revise the manuscript. The Alice Kaplan Institute for the Humanities at Northwestern University contributed financial support for publication.

The patient labor of the archivists and librarians at the repositories listed in the notes made available most of the sources on which this book is based. The staff of the Archivo General Municipal de Puebla and the Archivo General del Estado de Oaxaca; Berenise Bravo Rubio and Marco Antonio Pérez Iturbe at the Archivo Histórico del Arzobispado de México; Martha Whittaker at the Sutro Library at California State; Walter Brem and Theresa Salazar at the Bancroft Library; and Hortensia Calvo and David Dressing in the Latin American Library at Tulane also endured my questions and requests and shared their knowledge of the sources and history.

In Berkeley, colleagues and friends who commented on drafts and advised on the conceptualization of the project include Victor Goldgel Carballo, Steve Gross, Bea Gurwitz, Sarah Hines, John Kelleher, Larissa Kelly, Dan Lee, Brian Madigan, Sean McEnroe, Rob Nelson, Kinga Novak, Matt O’Hara, Abena Osseo-Asare, Sylvia Sellers-Garcia, Chris Shaw, and Sarah Wells. Linda Lewin and Mark Healey supplied scholarly and professional guidance early on and again at the end. The theoretical vision of William Hanks is apparent in several chapters. Margaret Chowning endured messy first chapters, refined arguments along the way, and remains an admired mentor, colleague, and friend. Bill Taylor's work on peasant politics and religion first drew me to the historical profession. I have often returned to his publications and teachings in search of good questions, or when the answer seemed to come too quickly.

In Mexico City, Miruna Achim, Claudia Agostoni, Adriana Rodríguez Delgado, Javier Salinas Sáenz, and Zeb Tortorici encouraged this work and provided food, café, or shelter. Brian Connaughton always inspires with his insights into religion and public discourse. Linda Arnold's determined indexing of Mexican archives has benefited numerous researchers, 
including me. From Seville, José Hernández Palomo came through in a critical moment.

At Washington University in Saint Louis, Jean Allman, Daniel Bornstein, Maggie Garb, Christine Johnson, Ahmet Karamustafa, Steve Miles, Tim Parsons, Mark Pegg, and Yuko Miki took an interest and welcomed me. Billy Acree, historian in disposition if not in name, merits special mention. At the Huntington Library I developed some of the book's themes in conversations with Lily Geismer, Claire Gherini, Brian Klopotek, Cynthia Nazarian, Michele Navakas, Katie Paugh, Jason Sharples, and Derek Burdette, who kindly shared his work on Mexican confraternities from afar. At Notre Dame, Karen Graubart, Alex Martin, Jaime Pensado, and Evan Ragland graciously advised a visitor. At Northwestern, for several years my institutional home, Ken Alder, Mariana Cracium, Brodie Fischer, Paul Gillingham, Sean Hanretta, Laura Hein, Daniel Immerwahr, Camilo Leslie, Melissa Macauley, Michelle Molina, Daniel Stolz, Helen Tilley, and Keith Woodhouse supported and encouraged me and the project in the final stages.

Research on rumors and flight into "regions of refuge" was first presented at the 2009 meeting of the American Society of Ethnohistory, at the invitation of Martha Few and with helpful comments from Mary Karasch and Noble David Cook. Jennifer Hughes made possible a lively symposium on "Epidemics and History" at the University of California, Riverside. Other portions of the book were developed in presentations at the Katz Center for Mexican Studies at the University of Chicago, the Klopsteg Lecture Series in the Science in Human Culture Program at Northwestern, and Yale's School of Medicine, in a workshop convened by Mariola Espinosa. I learned much on this last occasion from Diego Armus, Pablo Gómez, Gilberto Hochman, Adrián López-Denis, Steven Palmer, Julia Rodriguez, Gabriela Soto Laveaga, and Adam Warren. Early on, Adam shared unpublished work from his pioneering study of medicine and population management in Peru. I am grateful for his friendship and advice.

Amy Smith Bell, Peg Duthie, Roger Gathman, Margo Irvin, Nora Spiegel, and the two anonymous reviewers for Stanford University Press guided this volume to completion, with maps provided by Bill Nelson. Material in the second and third chapters appeared previously as "Enlightened Publics for Public Health: Assessing Disease in Colonial Mexico," Endeavour 37:I (March 20I3): 3-I2, and “'Like Herod's Massacre': Quarantines, Bourbon Reform, and Popular Protest in Oaxaca's Smallpox Epidemic, I796-I797," The Americas 69:2 (October 2012): 203-235.

More a part of it than they know, this book is for my parents, Crescencio and Laura, and grandparents, Juana, Leoncio, Mary Jo, and Russell, whose patience for works in progress is unsurpassed. 
This page intentionally left blank 


\section{Enlightened Immunity}




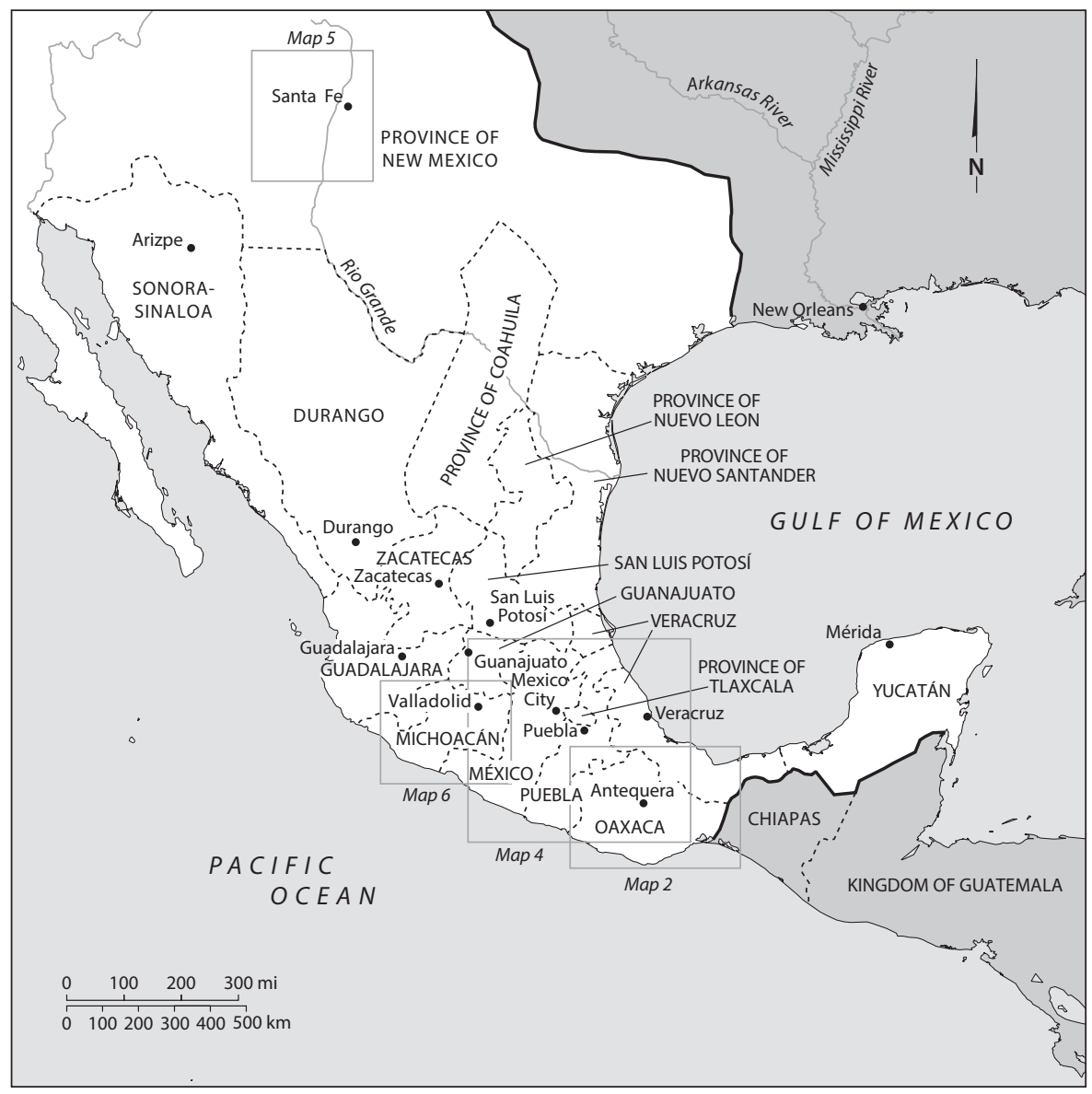

Map I. Viceroyalty of New Spain. 